Universidad de Salamanca.

Facultad de Medicina

Cátedra de Obstetricia y Ginecología.

Prof. Dr. Angel García Hernández
Obstetricia. Con 'Valium' amp. marcada aceleración del parto en $83 \%$ de los casos. En ninguno de los casos se encontraron efectos nocivos para la madre o el feto.

\title{
VALIUM. SU APLICACION EN EL PARTO
}

\author{
Por el Dr. Emilio Herrero Marcos
}

\begin{abstract}
"Hemos controlado 48 parturientas, de las cuales 16 eran primíparas, 10 secundíparas, 8 tercíparas y 14 grandes multíparas. A todas ellas se les administró 'Valium' en los distintos períodos del parto.

En seis casos comenzamos la administración apenas iniciado el período de dilatación, si bien ya hemos dejado expuestas las circunstancias especiales que concurrieron en ellos.

En los demás casos se comenzó la administración de 'Valium' con el parto bien establecido y en plena progresión.

En la medida que nos fue posible llevamos a efecto una preparación psíquica de la madre, lo que nos facilitó una decisiva cooperación por su parte.

Desde el momento que se inició la administración de 'Valium' la vigilancia a la mujer fue permanente: controlamos la contracción uterina, anotando número, intensidad y distancia entre cada contracción; tensión arterial, pulso y respiración, juntamente con el control de los latidos fetales.

La oxigenación de la madre fue constante.
\end{abstract}

\section{INTRODUCCION}

El deseo de disminuir el dolor en el parto, e incluso suprimirlo, ha sido un problema que siempre preocupó al tocólogo.

Desde muy antiguo determinados ritos y el empleo de brebajes fueron considerados remedios útiles con este fin. Más tarde el empleo de los anestésicos volátiles dejaron paso, allá por el año 1878, al opio, barbitúricos y escopolamina, que hicieron poner muy de moda el sueño crepuscular.

Los llamados anestésicos de conducción, para bloquear las vías nerviosas aferentes y el bloqueo con gangliopléjicos y otras drogas del sistema neurovegetativo, vienen a representar la antesala del problema tal y como se plantea en la actualidad.

Decimos problema porque la anestesia en el parto no puede considerarse, ni mucho menos, que haya sido admitida por la totalidad de los tocólogos. Nos atrevemos a decir que es, sin lugar a dudas, el tema que más controversias ha desencadenado. ¿Causas de estas controversias? Muchas, sin duda, pero citemos, sin entrar en comentarios, el que sea considerado el dolor del parto como fisiológico por unos, el atribuirle cierto papel otros, pero sobre todo el no haber llegado a una conclusión definitiva en cuanto a la medición de la intensidad del dolor se refiere.

Existe unanimidad de criterios en cuanto a la necesidad de la anestesia en las intervenciones obstétricas, pero esa unanimidad no se alcanza cuando de aliviar el dolor del parto se trata. También es justo decir que no hay unanimidad, pero sí mayoría que se inclina no solo por aliviar el dolor, sino por suprimirlo.

Esgrimen como justificación ciertos hechos que han venido a demostrar que el dolor no es imprescindible para una evolución normal del parto. A esto podenos añadir los conceptos emitidos recientemente, asegurando que el dolor no es, ni mucho menos, un hecho fisiológico, pues en realidad el dolor del parto representa el resultado de un esfuerzo a realizar para conseguir restablecer un equilibrio fisiológico perdido.

Dato muy digno de tener en cuenta y que predispone al éxito de la anestesia es nuestra influencia sobre la mujer, al prometerle que no sentirá dolores llegado el momento del parto, influencia que la libera por completo de un estado de ansiedad nada beneficioso para la evolución normal del mismo y que le abre un camino de tranquilidad con vistas a otros nuevos em'sarazos.

No podemos por menos de citar aquí la realidad de que la civilización, con su constante progreso, ha llevado a la mujer a una mayor sensibilización del sis'ema nervioso, lo que ha acarreado una disminución de la resistencia de la mujer al dolor. Todas estas circunstancias han ido imponiendo un criterio de crueldad en cuanto a la evolución fisiológica del parto se refiere, creando así la necesidad de suprimir el dolor en el parto.

La influencia favorable de la supresión del dolor sobre la aparición del shock obstétrico, la mayor tendencia a la administración de calmantes con no muy justificados motivos y el deseo de la mujer de verse aliviada en momento tan crítico, consideramos razones de peso para que poco a poco vayan desapareciendo los detractores de la anestesia en el parto.

No queremos dejar sentado un criterio sobre el particular, porque si las razones expuestas por los defensores de la anestesisa son merecedoras de tenerse en cuenta, consideramos que los argumentos en contra del empleo de los recursos anestésicos también han de ocupar un lugar preeminente. 
Lógicamente respetan el dolor en el parto los que lo consideran íntimamente unido a éste, e incluso favorable a la buena evolución del mismo. Si el dolor obliga a la parturienta a efectuar amplios ejercicios respiratorios, la anoxia fetal tendrá menos oportunidades de hacer acto de presencia. Contra este punto podemos decir que en sustitución de las grandes inspiraciones tenemos la abundante oxigenación, que el tocólogo puede facilitar a la mujer.

El hecho de que la anestesia haga pasar inadvertido el momento crítico del parto no sabemos qué repercusión puede tener sobre la madre, y del mismo modo dudamos sobre el efecto que puede ejercer la anestesia sobre el choque obstétrico, si anestesias más proiundas no evitan el choque que puede presentarse en otras intervenciones.

Muchos más son los argumentos esgrimidos por detractores y defensores de la anestesia en el parto, mas como nuestra intención al escribir este trabajo es la de exponer con todo rigor la experiencia obtenida por nosotros con la administración del preparado comercial 'Valium' lanzado al mercado por la casa Roche, vamos a dejar a un lado opiniones en pro y en contra y nos limitaremos a dar nuestros resultados, no sin antes exponer unas consideraciones generales que creemos de sumo interés el tener en cuenta antes de administrar algún anestésico.

Desde nuestro punto de vista, jamás deberá administrarse un anestésico si éste no es de simple aplicación, disminuye el dolor del parto hasta el punto de hacerlo tolerable y no representa peligro alguno para la madre. Aparte de lo anteriormente expuesto, creemos que está totalmente contraindicado el anestésico que interfiere la dinámica del parto y representa riesgo para el feto.

Quizá a lo largo de lo expuesto por nosotros se pueda interpretar que no somos, ni mucho menos, unos. partidarios a ultranza de la anestesia en el parto. A este respecto queremos decir que desde luego anteponemos la seguridad de la madre y el feto a cualquier recurso encaminado simplemente a proporcionar un parto más o menos doloroso. No admitimos justificación para exponer a un peligro a una mujer que ha de realizar un proceso fisiológico.

Basados en este criterio nos hemos prestado a recoger los resultados que hemos obtenido con la administración de 'Valium', producto que hemos elegido para nuestro trabajo porque no se trata de un verdadero anestésico, sino de un ansiolítico de acción miorrelajan Łe y tranquilizadora, cuyas cualidades consideramos "a priori" favorecedoras en la mitigación del dolor en el parto, disminución de la duración del mismo y carente de efectos secundarios sobre la madre y el feto.

\section{MATERIAL Y METODO}

El preparado que hemos utilizado para nuestro trabajo es un derivado de las benzodiazepinas conocido comercialmente con el nombre de 'Valium' similar al 'Librium', si bien es cinco veces más potente que éste. Su estructura química es la siguiente: y responde a la fórmula 7 - cloro - 1 - metil - 5 - fenil - $3 \mathrm{H}$ - 1,4 benzodiapezina - 2 ( $1 \mathrm{H}$ )-ona. Se trata de una base cristalina, insoluble en el agua, incolora, que fue sintetizada en el año 1961 por Sternbach y Reeder

Randall y colaboradores han estudiado experimentalmente en ratas su acción miorrelajante y tranquilizadora al comprobar la reducción de su actividad locomotora y disminuir la rigidez de descerebración.

Por vía intravenosa a dosis más elevadas, y sobre todo si se acelera su administración, tiene una marcada acción hipnótica, mientras que si se administra solamente por vía intramuscular su acción es simplemente ansiolítica y miorrelajante, pero sin llegar a hipnosis. Su eliminación se lleva a efecto en su 70 por 100 durante las primeras veinticuatro horas por la orina, mientras que el resto es eliminado en días sucesivos debido a la lentitud de entregas por parte de los tejidos a la sangre.

Nuestra casuística comprende un total de 48 mujeres, de las cuales la mayor parte fueron controladas en el servicio de Ginecología al que pertenecemos y el resto pertenecía a la clientela privada. A todas ellas, y llegado el momento del parto y en diferentes períodos del mismo, se les administró ' $V a$ alium' en dosis que nunca fueron inferiores a 10 miligramos ni sobrepasaron los 20 miligramos.

Este grupo de pacientes, al iniciarse el parto, se encontraba con la siguiente presentación: 0. 1. I. A., 36 (75 por 100); O. I. D. A., cinco $(10,4$ por 100); O. I. I. P., cinco $(10,4$ por 100$)$; nalgas, dos (4,16 por 100). De estas enfermas que nosotros hemos controlado el grado de paridad era el siguiente: Primíparas, 16 (33,33 por 100); secundíparas, 10 (20,83 por 100); tercíparas, ocho (16,66 por 100); grandes multíparas, $14(29,16$ por 100$)$.

La edad de las parturientas era como sigue: Hasta veintidós años, nueve (18 por 100); de veintidós a treinta y dos años, 32 ( 66 por 100); de treinta y dos a cuarenta y dos años, seis (12 por 100); más de cuarenta y dos años, dos (4 por 100).

En cuanto a las condiciones en que se encontraban los partos en el momento de la administración del 'Valium', 40 se encontraban en evolución normal y 7 con distocia dinámica 0 de dilatación.

Con respecto al grado de encajamiento, en 45 casos la presentación se encontraba en el III plano de Hodge $y$ tres casos en IV plano.

En ningún caso se administró el 'Valium' hasta que la dilatación cervical era de tres o cuatro: centímetros en las multíparas y de cinco centímetros en las primíparas.

De las 48 mujeres que componen nuestra casuística, tres primíparas, una secundípara y dos grandes multíparas iniciaron el trabajo del parto siendo portadoras de un gran miedo al mismo. Hemos de hacer notar que las seis enfermas pertenecían al medio rural, no habían sido controladas ni examinadas durante su gestación por tocólogo alguno y las circunstancias ambisntales en que viven determinó en las mismas un brusco cambio al ingresar en la clínica que se traduio en un estado de intranquilidad imposible de mitigar con simples razonamientos y consejos por nuestra parte.

Por todo lo expuesto administramos a estas seis mujeres 10 miligramos de 'Valium' por vía intramuscular, y transcurridos de veinticinco a treinta y cinco minutos su acción tranquilizadora fue manifiesta, lo que permitió un período de dilatación completamente normal. Llegada la dilatación a siete centímetros se procedió a instaurar un yoteo intravenoso de 10 unidades de hormona occitócica en 500 centímetros cúbicos de suero glucosado a una velocidad de 12 gotas por minuto y a la vez se inyectaron 10 miligramos de 'Valium' por la misma vía. A los pocos segundos estas mujeres entracon en un estado de indiferencia y calma psíquica, so- 
lamente interrumpido en el momento de máxima intensidad de la contracción. En las tres primíparas practicamos episiotomía medio-lateral y la terminación feliz del parto fue la norma en estas seis mujeres.

En los dos casos de presentación de nalgas nuestra conducta fue expectante hasta que la dilatación fue completa. En estos momentos administramos 10 miligramos de 'Valium' por vía intravenosa, comprobando que rápidamente se completaba la dilatación, y llegado el momento de practicar ayuda manual, para la salida del feto nuestras maniobras se vieron facilitadas por el estado de indiferencia de la mujer, que, por otra parte, respondió fácilmente a nuestras indicaciones.

En un caso fue necesaria la extracción fetal con fórceps. Se trataba de una mujer que llegó a nosotros tras varias horas de parto en su domicilio en el medio rural, sin personal sanitario a su lado. Ingresó en la clínica con bolsa de aguas rota, dilatación entre siete y ocho centímetros y sin prestar la más mínima colaboración para el desarrollo del parto. Presa de un miedo exagerado, hacía caso omiso de nuestras indicaciones.

Le administramos 10 miligramos de 'Valium' por vía intravenosa, previa la instauración del goteo de hormona occitócica, y no conseguimos que el parto se resolviera espontáneamente, si bien la dilatación se completó a los pocos minutos.

Como el feto comenzó a manifestar signos de sufrimiento practicamos un fórceps. Cinco miligramos más fueron suficientes para conseguir una medicación preanestética que potencializó el anestésico empleado (omitimos el nombre intencionadamente), logrando una anestesia profunda durante la aplicación del fórceps. El despertar fue tranquilo al cabo de dos minutos de haber suprimido el gas anestésico. Terminado el acto quirúrgico la respiración fue sosegada, dando la impresión de dormir un sueño placentero.

Respondió bien a los estímulos y mantuvo un estado analgésico respiratorio que le hizo tener la sensación de no haber sido intervenida.

Queremos dejar constancia de que el caso presente no ha sido interpretado por nosotros como el fracaso, pues hay que considerar que los datos que nos dieron los familiares no nos ofrecían garantía de su exactitud. No precisaban cuando comenzó el parto, no sabían con exactitud el momento de haber roto la bolsa de las aguas, no habiamos visto durante el embarazo a la mujer, por lo que ignorábamos sus formas de reaccionar, etc. Sin embargo, hay que anotar que del estado de intranquilidad que acusó en el momento de ingresar en la clínica se vio liberada fácilmente, y la dilatación, que no se había completado, se llevó a efecto rápidamente.

De los 40 casos restantes, en 18 la dosis llegó hasta 20 miligramos, pero solamente en uno de ellos se consiguió una anestesia total. En siete de estos 18 casos la dilatación no progresaba después de 8 horas, siendo espectacular con la rapidez que se llevó a efecto tras de la administración de 10 miligramos de 'Valium'. En estos 40 casos la evolución del parto fue espontánea. En todas las primíparas practicamos episiotomíamediolateral y en algunos casos ayudamos la expulsión fetal con la maniobra Kristeller.

La expulsión de la placenta se verificó espontáneamente, y siempre a la salida de la misma inyectamos una ampolla de Methergin, por vía endovenosa. En nueve casos de los estudiados por nosotros, las mujeres acusaron una discreta sensación de dolor en el trayecto de la vena inyectada, sensación que desapareció a los pocos segundos espontáneamente.

\section{CONCLUSIONES}

1a. El producto empleado por nosotros, expendido en el mercado por la casa Roche, bajo el nombre comercial 'Valium' 'Roche', se trata de un ansiolítico de acción cinco veces más potente que el 'Librium', de la misma casa.

2a. Este preparado ejerce una acción miorrelajante y tranquilizadora si se utiliza a dosis entre 10 y 20 miligramos en inyección intramuscular, manifestándose su efecto a partir de los veinticinco minutos.

3a. Por vía endovenosa la acción es muy rápida, apanas unos segundos, y a dosis de 20 miligramos puede algunas veces $(2,8$ por 100 entre nosotros) proporcionar una anestesia general.

4a. En el 83 por 100 de los casos comprobados por nosotros se consiguió una marcada aceleración del parto, determinando al mismo tiempo una mejor relajación de la parturienta.

5a. La recuperación plena de la conciencia se efec:uó en todos los casos de una manera rápida. La mujer se encontraba en un estado de quietud que la hacía olvidar de haber realizado esfuerzo alguno.

6a. Su efecto tranquilizante fue absolutamente favorable en siete casos ( 14 por 100). Estas mujeres, que ingresaron en la clínica siendo portadoras de verdadero terror al parto, al administrarles 10 miligramos de 'Valium' al iniciarse el período de dilatación por vía intramuscular las llevó a un estado de casi absoluta tranquilidad, que influyó de manera decisiva en la favorable evolución posterior del parto.

7 a. En un caso (2,08 por 100) que fue necesario terminar quirúrgicamente el parto (fórceps) supuso una excelente inducción para una anestesia más profunda, que se llevó a efecto posteriormente.

En estos casos el inmediato posoperatorio representó para la mujer un agradable estado que nada la hacía pensar había sido sometida a una intervención obstétrica.

8a. Si bien no ha sido investigado por nosotros en el presente trabajo, a la vista de los resultados obtenidos admitimos y aceptamos los trabajos de Thurias y colaboradores, los cuales dicen haber comprobado una disminución del tono basal del útero con la administración de 'Valium', lo que viene a determinar un efecto valorizador de la amplitud de la contracción uterina.

9a. En ningún caso hemos encontrado efectos secundarios nocivos para la madre o el feto.

\section{BIBLIOGRAFIA}

1-A. Seoane de Lucas y F. Azula Esturo: Rev. Española Anest. Rean., 15, 582-587 (1968).

2-M. Galbis y E. Fagoaga: Problemas fundamentales de la práctica obstétrica, 263-311 (1957).

3-V. Martín Sánchez: Rev. Española. Anest., 2, 112 (1955).

4-M. L. McCall y D. Sass: Am. J. Obst. Gyn., 71, 1089 (1956).

5-H. I. Norton, M. Weingarten y E. T. Mc Donough: Am. J. Obst. Gyn., 71-1251 (1956).

6-J. M. Trincado y V. Martín Sánchez: Rev. Española Obst. Gin., 14, 86 (1955).

7-J. Dexeus, J. Reixach y M. Alberti: Rev. Española Obst. Gin., 10, 1 (1953).

8-H. Dorr: Gynaecologia, 136, 65 (1953).

9-G. Aguirre: Med. Clin., 22, 178 (1954).

10-R. Ibáñez y J. Pardina Suñe: Anal. Cirg., 516-523 (1962). 